УДК 547.918:635.63

\title{
ВЛИЯНИЕ ГЛИКОЗИДОВ ХЕДЕРАГЕНИНА ИЗ САULOPНYLLUM ROBUSTUM MAX. НА РОСT КОРНЕЙ ПРОРОСТКОВ CUCUMIS SATIVUS L.
}

\author{
(ㄱ) М.М. Анисимов", Е.Л. Чайкина
}

Тихоокеанский институт биоорганической химии им. Г.Б. Елякова

Дальневосточного отделения РАН, пр. 100-летия Владивостока, 159, Владивосток, 690022 (Россия), e-mail: anisimov@piboc.dvo.ru

Исследовано рострегулирующее действие тритерпеновых гликозидов хедерагенина - каулозидов A, C, D и G, выделенных из Caulophyllum robustum Maxim., на рост корня проростков Cиситis sativus L. Установлено, что эффективность рострегулирующего действия исследованных соединений зависит от их химического строения. Каулозиды А и С имеют одну углеводную цепь. В концентрации 500 и 100 мкг/мл они оказывали ингибирующий эффект на рост корней проростков Cucumis sativus (10,3 и 20,4\% соответственно). Каулозиды D и G имеют две углеводные цепи. Эти соединения не проявляли ингибирующего эффекта на рост корней в концентрациях до 500 мкг/мл, но в концентрациях 100 и 250 мкг/мл проявляли небольшое стимулирующее действие $(9,1$ и 10,4\%). Ингибирующее действие каулозида С в первую очередь направлено на проростки с интенсивно растущим основным корнем.

Ключевые слова: тритерпеновые гликозиды, фиторегулирующая активность, проростки Cucumis sativus, ингибиторы роста растений.

\section{Введение}

Дальневосточное растение Caulophyllum robustum Maxim. представляет особый интерес как сырьевой источник биологически активных веществ. Это растение является продуцентом уникальных биорегуляторов тритерпеновой природы гликозидов хедерагенина: каулозидов А, C, D, G [1-4]. Как следует из анализа литературных данных, содержащиеся в растениях каулозиды A, C, D, G обладают широким спектром медико-биологического действия, в том числе цитотоксическим в отношении опухолевых клеток, эмбрионов морского ежа и дрожжей [5-8]. Каулозид С избирательно ингибирует размножение грибной микрофлоры, в то время как грамположительные и грамотрицательные бактерии оказались нечувствительными к действию этого гликозида в концентрациях до 500 мкг/мл [9]. Кроме того, каулозид С стимулирует пролиферацию фибробластов эмбриона человека. Наблюдаемый эффект вызван ионами кальция, которые поступают из среды в клетку через поры, индуцируемые в мембранах каулозидом С [10, 11]. Калиевая соль каулозида С стимулирует регенерацию кожи при раневых и ожоговых поражениях [12]. Каулозид С способен проникать через плазматические мембраны опухолевых клеток и взаимодействовать с лизосомами [13]. Это, в свою очередь, приводит к нарушению проницаемости лизосомальных мембран [7] и утрате жизнеспособности опухолевых клеток.

Настоящая работа проводилась с целью изучения влияния тритерпеновых гликозидов каулозидов А, C, D и G, выделенных из корней и корневищ дальневосточного растения Caulophyllum robustum Maxim,. на рост основного корня проростков Cucumis sativus L. сорта Каскад.

Анисимов Михаил Михайлович - доктор биологических наук, профессор, e-mail: anisimov@piboc.dvo.ru Чайкина Елена Леонидовна - научный сотрудник, e-mail: anisimov@piboc.dvo.ru

\section{Экспериментальная часть}

В качестве испытуемых веществ использовали хедерагенин и каулозиды A, C, D и G, которые

\footnotetext{
* Автор, с которым следует вести переписку.
} 
были выделены из метанольного экстракта корней дальневосточного реликтового растения Caulophyllum robustum Maxim. [1] и отличались друг от друга моносахаридным составом и местом присоединения углеводной цепи к агликону (табл. 1).

В качестве биологического теста использовали семена Cucumis sativus L. сорта Каскад. Для оценки биологического действия испытуемых веществ использовали технику проращивания семян в рулонах фильтровальной бумаги [14]. Семена раскладывали на полосы фильтровальной бумаги размером $12 \times 42$ см, предварительно смоченной испытуемым раствором, свертывали в рулоны, помещали в стаканы с небольшим количеством испытуемого раствора (100 мл) и оставляли на трое суток в термостате при 25$26^{\circ} \mathrm{C}$. После инкубации у проростков измеряли длину главного корня. Результаты испытаний оценивали как среднее арифметическое четырех повторных опытов (по 25 семян в каждом) и выражали в процентах от контрольных образцов (M $\pm \mathrm{sd})$. Для статистической обработки использовали компьютерную программу ORIGIN 7.0. Достоверность результатов оценивали с помощью $t$-критерия Стьюдента $(\mathrm{p}<0,05)$.

Таблица 1. Химическое строение гликозидов хедерагенина, выделенных из Caulophyllum robustum Maxim.

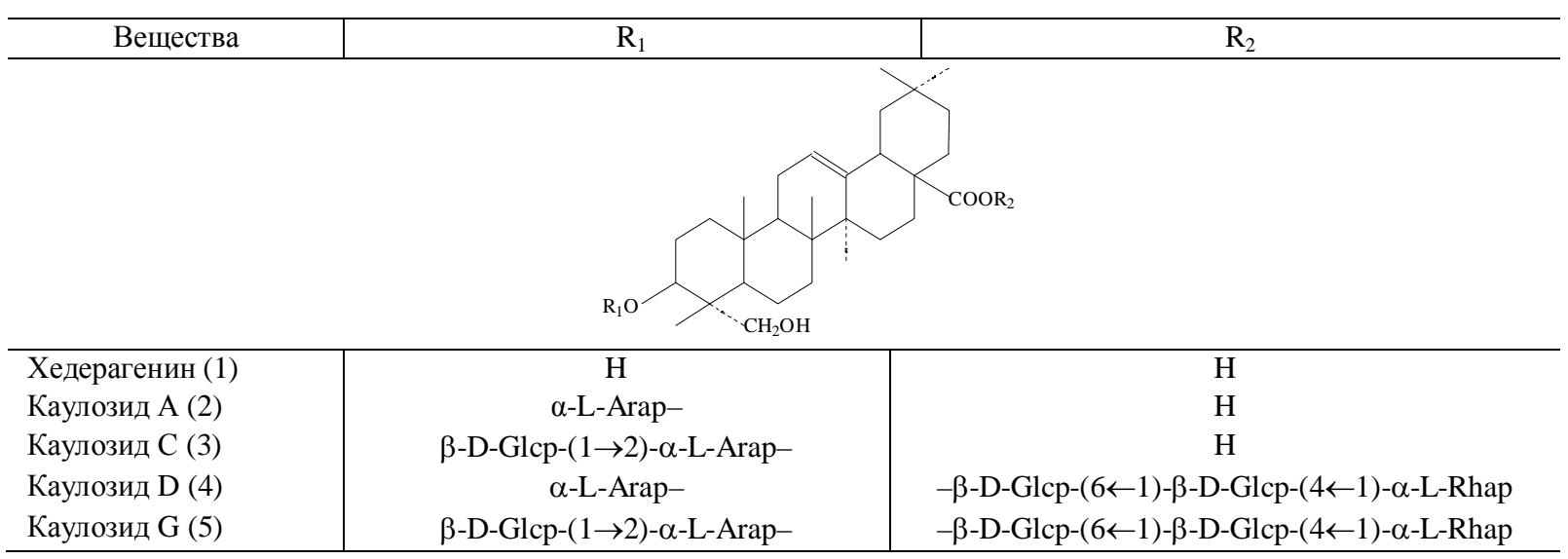

\section{Обсуждение результатов}

Семена и проростки огурца используются в качестве биологического теста при исследовании свойств аллелохимических соединений [15]. Известно, что существующие подходы позволяют оценивать действие биологически активных веществ на всю популяцию семян, хотя по скорости прорастания семена являются разнородными. В зависимости от интенсивности роста растений они могут по-разному реагировать на действие химических соединений [16-18].

Хедерагенин (1) практически не оказывал влияния на рост корня проростков Cucumis sativus (табл. 2). Каулозид А имеет одну углеводную цепь с одним моносахаридным остатком арабинозой при С-3 хедерагенина (табл. 1). Он проявлял слабое ингибирующее действие на рост основного корня проростков Cucumis sativus. Так, при концентрации этого соединения 500 мкг/мл длина основного корня была на 10,3\% короче по сравнению с контролем (табл. 2). Каулозид А при концентрации 10 мкг/мл проявлял лишь тенденцию к стимуляции роста корней проростков огурца $(4,5 \%)$.

Таблица 2. Фиторегулирующая активность гликозидов хедерагенина на проростках Cucumis sativus L.

\begin{tabular}{|c|c|c|c|c|c|}
\hline Вещества & $\begin{array}{c}\text { Концентрация, } \\
\text { мкг/мл } \\
\end{array}$ & $\begin{array}{c}\text { Длина корня, } \\
\text { процент к контролю }\end{array}$ & Вещества & $\begin{array}{c}\text { Концентрация, } \\
\text { мкг/мл }\end{array}$ & $\begin{array}{c}\text { Длина корня, } \\
\text { процент к контролю }\end{array}$ \\
\hline \multirow{5}{*}{1} & 0 & $100,0 \pm 2,2$ & \multirow{5}{*}{4} & 0 & $100,0 \pm 3,1$ \\
\hline & 10 & $104,6 \pm 5,1$ & & 10 & $101,8 \pm 3,6$ \\
\hline & 100 & $98,5 \pm 3,1$ & & 100 & $109,1 \pm 3,6$ \\
\hline & 250 & $105,0 \pm 3,1$ & & 250 & $98,0 \pm 5,3$ \\
\hline & 500 & $100,3 \pm 1,1$ & & 500 & $102,7 \pm 1,3$ \\
\hline \multirow{5}{*}{2} & 0 & $100,0 \pm 1,4$ & \multirow{5}{*}{5} & 0 & $100,0 \pm 4,2$ \\
\hline & 10 & $104,5 \pm 5,3$ & & 10 & $102,0 \pm 6,3$ \\
\hline & 100 & $100,5 \pm 2,7$ & & 100 & $102,5 \pm 0,4$ \\
\hline & 250 & $98,8 \pm 2,1$ & & 250 & $110,4 \pm 4,9$ \\
\hline & 500 & $89,7 \pm 3,5$ & & 500 & $98,7 \pm 4,4$ \\
\hline
\end{tabular}


Каулозид С имеет также одну углеводную цепь, но с двумя моносахаридными остатками, арабинозой и глюкозой, при С-3 хедерагенина (табл. 1). Это соединение проявило ингибирующий эффект на рост корней проростков огурца при концентрации уже 100 мкг/мл. При этом средняя длина основного корня была на 20,4\% короче по сравнению с контролем (табл. 3). Наиболее чувствительны к ингибирующему действию каулозида С были интенсивно растущие проростки. Так, при концентрациях этого соединения 100,250 и 500 мкг/мл количество проростков с длиной корня 21-40 мм увеличилось, а количество проростков с длиной корня 61-80 значительно уменьшилось. Каулозид С при концентрации 10 мкг/мл проявил лишь тенденцию к стимуляции роста корней проростков огурца $(8,2 \%)$. При этом уменьшилось количество проростков с длиной корня 21-40 мм и значительно увеличилось количество проростков с длиной корня 61-80 и 81-100 мм. Таким образом, каулозид С с двумя моносахаридными остатками оказался более активным по сравнению с каулозидом A, у которого углеводная цепь состояла из одного моносахаридного остатка.

Каулозид D отличается от каулозида А присутствием второй углеводной цепи при С-28 хедерагенина, состоящей из остатка рамнозы и двух остатков глюкозы (табл. 1). Это соединение не проявляло ингибирующего эффекта на рост корней в концентрациях до 500 мкг/мл (табл. 2). При концентрации каулозида D 100 мкг/мл отмечалось увеличение средней длины основного корня на 9,1\%. При этом количество проростков с длиной основного корня 61-80 мм увеличилось с 53 до 71\%, а количество проростков с длиной основного корня 41-60 мм уменьшилось с 36 до 22\% (табл. 3).

Каулозид $\mathrm{G}$ отличается от каулозида $\mathrm{C}$ присутствием второй углеводной цепи при С-28 хедерагенина, состоящей и остатка рамнозы и двух остатков глюкозы (табл. 1). Это соединение не проявляло ингибирующего эффекта на рост корней в концентрациях до 500 мкг/мл (табл. 2). При концентрации каулозида G 250 мкг/мл отмечалось увеличение средней длины основного корня на 10,4\%. При этом количество проростков с длиной основного корня 61-80 мм увеличилось с 64 до 80\%, а количество проростков с длиной основного корня 41-60 мм уменьшилось с 28 до $8 \%$.

Гликозиды хедерагенина, у которых водород карбоксильной группы при С-28 замещен на углеводную цепь из трех моносахаридных остатков, не проявляли ингибирующего действия на рост корней проростков огурца. Результаты этих исследований согласуются с литературными данными, согласно которым все одноцепочные гликозиды хедерагенина, идентичные каулозидам А и С, проявляли высокую моллюскоцидную активность. Двуцепочные гликозиды, идентичные каулозидам D и G, были неактивны [19, 20]. Аналогичные данные получены по противомикробной активности каулозидов А, C, D и G [5].

Из всех изученных соединений каулозид С (3) проявлял более выраженную ингибирующую активность на рост корня проростков Cucumis sativus L. (табл. 3). При этом ингибирующее действие каулозида C в первую очередь направлено на проростки с интенсивно растущим основным корнем. В то же время проростки с медленно растущим основным корнем оказались менее чувствительны к высоким концентрациям каулозида С. Возможно, что в естественных условиях при аллелопатическом взаимодействии растений в фитоценозах рост-ингибирующее действие тритерпеновых гликозидов направлено не на всю популяцию растений-конкурентов, а на ее интенсивно растущую часть. Результаты наших исследований согласуются с литературными данными, согласно которым механизм ингибирующего действия веществ тритерпеновой природы на линейный рост корешков растений связан с тем, что они снижают митотическую активность интенсивно делящихся клеток $[21,22]$.

Таблица 3. Рост-регулирующая активность каулозидов C, D и G

\begin{tabular}{|c|c|c|c|c|c|c|c|}
\hline \multirow{3}{*}{ Вещества } & \multirow{3}{*}{$\begin{array}{c}\text { Концентрация, } \\
\text { мкг/мл }\end{array}$} & \multirow{3}{*}{$\begin{array}{c}\text { Длина корня, } \\
\text { процент к контролю }\end{array}$} & \multicolumn{5}{|c|}{ Длина основного корня, мм } \\
\hline & & & $<21$ & $21-40$ & $41-60$ & $61-80$ & $81-100$ \\
\hline & & & \multicolumn{5}{|c|}{ количество проростков, \% } \\
\hline \multirow{5}{*}{3} & 0 & $100,0 \pm 1,0$ & 0 & 3 & 35 & 61 & 1 \\
\hline & 10 & $108,2 \pm 2,4$ & 0 & 3 & 15 & 75 & 7 \\
\hline & 100 & $79,6 \pm 3,4$ & 0 & 14 & 76 & 10 & 0 \\
\hline & 250 & $70,3 \pm 5,0$ & 0 & 28 & 69 & 3 & 0 \\
\hline & 500 & $62,5 \pm 2,8$ & 0 & 55 & 45 & 0 & 0 \\
\hline \multirow{2}{*}{4} & 0 & $100,0 \pm 3,1$ & 0 & 7 & 36 & 53 & 4 \\
\hline & 100 & $109,1 \pm 3,6$ & 0 & 1 & 22 & 71 & 6 \\
\hline \multirow{2}{*}{5} & 0 & $100,0 \pm 4,2$ & 0 & 3 & 28 & 64 & 5 \\
\hline & 250 & $110,4 \pm 4,9$ & 0 & 1 & 8 & 80 & 11 \\
\hline
\end{tabular}


Таким образом, гликозиды хедерагенина обладают фиторегулирующими свойствами. Подобные эффекты наблюдали и другие авторы [18, 23-25].

Из литературных источников известно, что тритерпеновые гликозиды образуют со стеринами мембран комплексы [26] и формируют каналы [27], через которые из клеток выходят ионы калия [28], УФпоглощающие вещества [29], ортофосфаты и аминный азот [30]. По мере утечки из клеток низкомолекулярных соединений ингибируется рост грибов [29], проявляется цитотоксическая активность [13], ингибируется развитие эмбрионов морского ежа [29]. Возможно, что каулозид С связывается со стеринами мембран клеток корней, изменяет их проницаемость и в конце концов замедляет рост корней проростков $C u$ cumis sativus L. Что же касается стимулирующего действия, то этот вопрос не изучен.

\section{Bыводы}

Каулозиды А и С имеют одну углеводную цепь. В концентрации 500 и 100 мкг/мл они оказывали ингибирующий эффект на рост корней проростков Cucumis sativus (10,3 и 20,4\% соответственно). Ингибирующее действие каулозида С в первую очередь направлено на проростки с интенсивно растущим основным корнем. Каулозиды D и G имеют две углеводные цепи. Эти соединения не проявляли ингибирующего эффекта на рост корней в концентрациях до 500 мкг/мл, но в концентрациях 100 и 250 мкг/мл проявляли небольшое стимулирующее действие $(9,1$ и 10,4\%).

\section{Список литературы}

1. Стригина Л.И., Четырина Н.С., Еляков Г.Б. Тритерпеновые гликозиды Caulophyllum robustum // Химия природных соединений. 1970. №5. С. 552-555.

2. Стригина Л.И., Четырина Н.С., Исаков В.В. Каулозид G - новый тритерпеновый гликозид из Caulophyllum robustum. Идентификация каулозида С // Химия природных соединений. 1976. №5. С. 619-623.

3. Strigina L.I., Chetyrina N.S., Isakov V.V., Elkin Yu.N., Dzizenko A.K., Elyakov G.B. Cauloside D a new triterpenoid glycoside from Caulophyllum robustum Maxim.: Identification of cauloside A // Phytochemistry. 1975. Vol. 14. Pp. $1583-1586$.

4. Анисимов М.М., Стригина Л.И., Горовой П.Г., Аминин Д.Л., Агафонова И.Г. Химический состав и медикобиологические свойства тритерпеновых гликозидов дальневосточного растения Caulophyllum robustum (ceмейство Berberidaceae) // Раст. ресурсы. 2000. Т. 36, вып. 1. С. 107-129.

5. Анисимов М.М., Стригина Л.И., Баранова СИ., Кульга А.Л., Четырина НС. Об антимикробной активности тритерпеновых гликозидов из Caulophyllum robustum Maxim. // Антибиотики. 1972. Т. 17. №9. С. 834-837.

6. Анисимов М М., Фронэрт Е.Б., Стригина Л.И., Четырина Н.С. Влияние тритерпеновых гликозидов из Саиlophyllum robustum Maxim. на ранний эмбриогенез морского ежа // Фармакология и токсикология. 1974. №2. C. 211-214.

7. Прокофьева Н.Г., Анисимов М.М., Стригина Л.И., Киселева М.И., Гафуров Ю.М. Влияние реакции среды на цитотоксическую и противоопухолевую активность тритерпенового гликозида каулозида С // Материалы III Всесоюзного совещ. «Актуальные проблемы экспериментальной химиотерапии опухолей». Черноголовка, 1987. C. $106-108$.

8. Anisimov M.M., Shentsova K.B., Shcheglov V.V., Strigina L.I., Chetyrina N.S., Aladjina K.G., Vecherko L.P., Zorina A.D., Matyukhina L.G. and Saltykova L.A. Toxic effects of certain pentacyclic triterpenoids on early embryogenesis of the sea urchin // Toxicon. 1976. Vol. 14. Pp. 259-265.

9. Щеглов В.В., Баранова С.И., Анисимов М.М., Антонов А.С., Афиятуллов Ш.Ш., Левина Э.В., Шарыпов В.Ф., Стоник В.А., Еляков Г.Б. Изучение антимикробного спектра действия некоторых тритерпеновых и стероидных гликозидов // Антибиотики. 1979. №4. С. 270-273.

10. Likhatskaya G.N., Aminin D.L., Agafonova I.G, Gnedoi S.N., Shentsova E.B., Strigina LI., Anisimov M.M. The ph-dependent channels formed by cauloside C //Saponins used in food and agriculture. New York, 1996. Pp. 239-249.

11. Aminin D.L., Agafonova I.G., Gnedoi S.N., Strigina L.I., Anisimov MM. The effect of pH on biological activity of plant cytotoxin cauloside C // Comp. Biochem. Physiol. 1999. Vol. 102A. Pp. 45-51.

12. Патент № 2078086 (РФ). Калиевая сель Каулозида С, стимулирующая репаративную регенерацию кожи / Д.Л. Аминин, Л.И. Стригина, И.Г. Агафонова, Е.В. Шевцова, М.М. Анисимов, Ю.С. Хотимченко, И.В. Добрынченко / 1997. С. 97.

13. Прокофьева Н.Г., Лихацкая Г.Н., Аминин Д.Л., Гафуров Ю.М., Сасункевич В.А., Стригина Л.И., Анисимов М.M. Механизм взаимодействия рН-зависимого цитостатика каулозида С с мембранами опухолевых клеток и липосомами // Известия АН СССР. Серия биология. 1990. №3. С. 338-342.

14. Анисимов М.М., Логачев В.В., Демина Е.А, Самошина Н.Ф., Денисенко М.В., Уварова Н.И. Структурнофункциональные свойства тритерпеноидов ряда лупана. 4. Влияние бетулина и его структурных аналогов на рост корня проростков Cuсumis sativus L. сорта Каскад // Растительные ресурсы. 2006. T. 42, вып. 3. С. $74-81$. 
15. Lehman M.E., Blum U. Influence of pretreatment stresses on inhibitory effects of ferulic acid, an allelopathic phenolic acid // J. Chem. Ecol. 1999. Vol. 25. Pp. 1517-1529.

16. Анисимов М.М., Стехова С.И., Похило Н.Д. Влияние бетулафолиентетраола на рост корня проростков $C u$ cumis sativus L. // Растительные ресурсы. 1998. Вып. 3. С. 103-106.

17. Анисимов М.М., Петрова О.М., Логачев В.В., Донец Е.А., Горовой П.Г. Влияние водно-этанольного экстракта из Caulophyllum robustum Maxim на рост корня проростков Cucumis sativus L. // Растительные ресурсы. 2000. Вып. 4. С. 100-105.

18. Анисимов М.М., Логачев В.В., Сильченко А.С., Авилов С.А. Влияние тритерпеновых гликозидов голотурии Cucumaria japonica на рост корня проростков Cucumis sativus L. // Известия АН. Серия биология. 2004 . №4. C. $505-512$.

19. Hostettmann K., Kizu H., Tomimori T. Molluscicidal properties of various saponins // Planta med. 1982. Vol. 44. Pp. 34-35.

20. Abdel-Gawad M.M., El-Nahas H.A., El-Sayed M.M. and Abdel-Hameed, E.S. Phytochemical investigation and molluscicidal activity of Oreopanax reticulatum Donn // Bull. Pharm. Sci., Assiut University. 2004. Vol. 27. Part 1. Pp. 99-111.

21. Boiteau P., Pasich B., Patismanga A.R. The triperpenoids in plant and animal physiology. Paris, 1964. 1360 p.

22. Nord E.C., van Atta G.R. Saponin a seed germination inhibitor // Forest. Sci. 1960. Vol. 6. Pp. 350-353.

23. Gumnicka O., Oleszek W. Triterpene saponins from the aerial parts of Dianthus caryophyllus var remontant Hort // Acta Soc. Bot. Pol. 1998. Vol. 67. Pp. 65-68.

24. Hiradate S., Yada H., Ishii T., Nakajima N., Ohnishi-Kameyama M., Sugie H., Zungsontiport S., Fujii Y. Three plant growth inhibiting saponins from Duranta repens // Phytochem. 1999. Vol. 52. Pp. 1223-1228.

25. Tsurumi S., Ishizava K., Rahman A., Soga K., Hoson T., Goto N., Kamisaka S. Effects of chromosaponin I and brassinolide on the growth of roots in etiolate Arabidopsis seedligs // Plant Physiol. 2000. Vol. 156. Pp. 60-67.

26. Лихацкая Г.Н., Яровая Т.П., Руднев В.С., Попов А.М., Анисимов М.М., Ровин Ю.Г. Образование комплекса тритерпенового гликозида голотурина А с холестерином в липосомальных мембранах // Биофизика. 1985. Вып. 2. С. 358-359.

27. Лихацкая Г.Н., Анисимов М.М. Молекулярные механизмы мембранотропного действия сапонинов // Тезисы докладов II съезда биофизиков России. М., 1999. С. 532-533.

28. Kalinin V.I., Volkova O.V., Likhatskaya G.N., Prokofieva N.G., Agafonova I.G., Anisimov M.M., Avilov S.A., Stonik V.A. Hemolytic activity of triterpene glycosides from the Cucumariidae family holothurians and evolution of this group of toxins // J. Nat. Toxins. 1992. Vol. 1. Pp. 17-30.

29. Анисимов М.М., Иванов А.С., Попов А.М., Киселева М.И., Себко И.Г., Коротких Л.Я., Антонов А.С., Стоник В.А., Антонов В.Ф. Влияние некоторых тритерпеновых гликозидов и полиеновых антибиотиков на проницаемость клеточных мембран для ионов $\mathrm{K}^{+}$и УФ-поглощающих веществ // Прикладная биохимия и микробиология. 1981. Вып. 6. С. 890-895.

30. Щеглов В.В., Баранова С.И., Анисимов М.М., Антонов А.С., Афиятуллов Ш.Ш., Левина Э.В., Шарыпов В.Ф., Стоник В.А., Еляков Г.Б. Изучение антимикробного спектра действия некоторых тритерпеновых и стероидных гликозидов // Антибиотики. 1979. №4. С. 270-273.

Поступило в редакичию 13 февраля 2014 г. После переработки 7 апреля 2014 г.

Anisimov M.M. , Chaikina E.L. THE INFLUENCE GLYCOSIDES OF HEDERAGENIN FROM THE CAULOPHYLLUM ROBUSTUM MAX. ON THE GROWTH OF ROOTS OF SEEDLINGS OF CUCUMIS SATIVUS L.

G.B. Elyakov Pacific Institute of Bioorganic Chemistry Far Eastern Branch, Russian Academy of Sciences, pr. 100-letija

Vladivostoka, 159, Vladivostok, 690022 (Russia),e-mail: anisimov@piboc.dvo.ru

The effects of growth regulators triterpene glycosides hederagenin - caulosides A, C, D and G, isolated from Caulophyllum robustum Maxim. on root growth of seedlings Cucumis sativus L. were studied Seeds were germinated in rolls of filter paper. The efficiency of growth regulatory actions investigated compounds depends on their chemical structure. Caulosides A and C have the one carbohydrate chain. These compounds exert an inhibitory effect on the growth of seedling roots Cucumis sativus (10,3 and 20,4 $\%$ respectively) at concentrations of 500 and $100 \mu / \mathrm{ml}$. Caulosides D and G have two carbohydrate chains. These compounds no exert an inhibitory effect on the growth of seedling roots Cucumis sativus at concentrations of $500 \mu / \mathrm{ml}$. Caulosides D and G exert small stimulating effect at concentrations of $100(9,1 \%)$ and $250(10,4 \%) \mu / \mathrm{ml}$ respectively.

Keywords: triterpenes glycosides, roots, saponins, Cucumis sativus, plant-growth, biologically active, growth-inhibitory action.

\footnotetext{
* Corresponding author.
} 


\section{References}

1. Strigina L.I., Chetyrina N.S., Eljakov G.B. Himija prirodnyh soedinenij, 1970, no. 5, pp. 552-555. (in Russ.).

2. Strigina L.I., Chetyrina N.S., Isakov V.V. Himija prirodnyh soedinenij, 1976, no. 5, pp. 619-623. (in Russ.).

3. Strigina L.I., Chetyrina N.S., Isakov V.V., Elkin Yu.N., Dzizenko A.K., Elyakov G.B. Phytochemistry, 1975, vol. 14, pp. 1583-1586.

4. Anisimov M.M., Strigina L.I., Gorovoj P.G., Aminin D.L., Agafonova I.G. Rastitel'nye resursy, 2000, vol. 36, no. 1, pp. 107-129. (in Russ.).

5. Anisimov M.M., Strigina L.I., Baranova SI., Kul'ga A.L., Chetyrina NS. Antibiotiki, 1972, no. 9, pp. 834-837. (in Russ.).

6. Anisimov M M., Fronjert E.B., Strigina L.I., Chetyrina N.S. Farmakologija i toksikologija, 1974, no. 2, pp. $211-214$. (in Russ.).

7. Prokof'eva N.G., Anisimov M.M., Strigina L.I., Kiseleva M.I., Gafurov Ju.M. Materialy III Vsesojuznogo soveshh. "Aktual'nye problemy eksperimental'noj himioterapii opuholej". [Proceedings of the III All-Union soveshch. "Actual problems of experimental cancer chemotherapy"]. Chernogolovka, 1987. pp. 106-108. (in Russ.).

8. Anisimov M.M., Shentsova K.B., Shcheglov V.V., Strigina L.I., Chetyrina N.S., Aladjina K.G., Vecherko L.P., Zorina A.D., Matyukhina L.G., Saltykova L.A. Toxicon, 1976, vol. 14, pp. 259-265.

9. Shheglov V.V., Baranova S.I., Anisimov M.M., Antonov A.S., Afijatullov Sh.Sh., Levina Je.V., Sharypov V.F., Stonik V.A., Eljakov G.B. Antibiotiki, 1979, no. 4, pp. 270-273. (in Russ.).

10. Likhatskaya G.N., Aminin D.L., Agafonova I.G, Gnedoi S.N., Shentsova E.B., Strigina L.I., Anisimov M.M. Saponins used in food and agriculture. New York: Plenum Press, 1996, pp. 239-249.

11. Aminin D.L., Agafonova I.G., Gnedoi S.N., Strigina L.I., Anisimov MM. Comp. Biochem. Physiol. 1999, vol. 102A, pp. $45-51$.

12. Patent 2078086 (RU). 1997. (in Russ.).

13. Prokof'eva N.G., Lihatskaja G.N., Aminin D.L., Gafurov Ju.M., Sasunkevich V.A., Strigina L.I., Anisimov M.M. Izvestija AN SSSR. Serija biologija. 1990, no. 3, pp. 338-342. (in Russ.).

14. Anisimov M.M., Logachev V.V., Demina E.A, Samoshina N.F., Denisenko M.V., Uvarova N.I. Rastitel'nye resursy, 2006, vol. 42, no. 3, pp. 74-81. (in Russ.).

15. Lehman M.E., Blum U. J. Chem. Ecol. 1999, vol. 25, pp. 1517-1529.

16. Anisimov M.M., Stehova S.I., Pohilo N.D. Rastitel'nye resursy, 1998, no. 3, pp. 103-106. (in Russ.).

17. Anisimov M.M., Petrova O.M., Logachev V.V., Donec E.A., Gorovoj P.G. Rastitel'nye resursy, 2000, no. 4, pp. 100105. (in Russ.).

18. Anisimov M.M., Logachev V.V., Sil'chenko A.S., Avilov S.A. Izvestija AN. Serija biologija. 2004, no. 4, pp. 505512. (in Russ.).

19. Hostettmann K., Kizu H., Tomimori T. Planta med. 1982, vol. 44, pp. 34-35.

20. Abdel-Gawad M.M., El-Nahas H.A., El-Sayed M.M. and Abdel-Hameed, E.S. Bull. Pharm. Sci., Assiut University. 2004, vol. 27, no. 1, pp. 99-111.

21. Boiteau P., Pasich B., Patismanga A.R. The triperpenoids in plant and animal physiology. Paris: Gauthier-Villars, 1964, $1360 \mathrm{p}$.

22. Nord E.C., van Atta G.R. Forest. Sci. 1960, vol. 6, pp. 350-353.

23. Gumnicka O., Oleszek W. Acta Soc. Bot. Pol. 1998, vol. 67, pp. 65-68.

24. Hiradate S., Yada H., Ishii T., Nakajima N., Ohnishi-Kameyama M., Sugie H., Zungsontiport S., Fujii Y. Phytochem, 1999, vol. 52, pp. 1223-1228.

25. Tsurumi S., Ishizava K., Rahman A., Soga K., Hoson T., Goto N., Kamisaka S. Plant Physiol. 2000, vol. 156, pp. 60-67.

26. Lihackaja G.N., Jarovaja T.P., Rudnev V.S., Popov A.M., Anisimov M.M., Rovin Ju.G. Biofizika, 1985, no. 2, pp. 358-359. (in Russ.).

27. Lihackaja G.N., Anisimov M.M. Tezisy dokladov II c\#ezda biofizikov Rossii. [Abstracts II congress of Russian biophysicists]. Moscow, 1999, pp. 532-533. (in Russ.).

28. Kalinin V.I., Volkova O.V., Likhatskaya G.N., Prokofieva N.G., Agafonova I.G., Anisimov M.M., Avilov S.A., Stonik V.A. J. Nat. Toxins. 1992, vol. 1, pp. 17-30.

29. Anisimov M.M., Ivanov A.S., Popov A.M., Kiseleva M.I., Sebko I.G., Korotkih L.Ja., Antonov A.S., Stonik V.A., Antonov V.F. Prikladnaja biohimija i mikrobiologija, 1981, no. 6, pp. 890-895. (in Russ.).

30. Shheglov V.V., Baranova S.I., Anisimov M.M., Antonov A.S., Afijatullov Sh.Sh., Levina Je.V., Sharypov V.F., Stonik V.A., Eljakov G.B. Antibiotiki, 1979, no. 4, pp. 270-273. (in Russ.). 